\title{
Training Of Trainer E-Learning Bagi Admin Di Sekolah Tingi Agama Islam Lukman Edy (STAILE) Pekanbaru
}

\author{
Zamzami ${ }^{1}$, Didik Siswanto ${ }^{2}$, Muhammad Sadar ${ }^{3}$ \\ Program Studi Teknik Informatika Fakultas Ilmu Komputer Universitas Lancang Kuning \\ Jl. Yossudarso KM. 8 Rumbai, Pekanbaru, Riau, Telp. 08117532015 \\ Email : zamzami@unilak.ac.id ${ }^{1}$, didik@unilak.ac.id², sadar@unilak.ac.id ${ }^{3}$
}

\begin{abstract}
Abstrak: Pada yayasan laman emas riau bangkit memeiliki banyak jenjang pendidikan di bawahnya seperti pendidikan Sekolah Tinggi Agama Islam Lukman Edi (STAILe), pendidikan formal dibawah jenjang perguruan tinggi juga seperti MTS (Madrasah Tsanawiyah) Serta MA (madrasah Aliah). Masa pandemic seperti saat ini membuat segala sektor usaha dan bisnis menjadi terganggu, begitu juga berdampak kepada dunia pendidikan. Banyak sekarang sistem pembelajaran maupun sistem perkuliahan beralih menjadi online dikarenakan mengikuti protokol kesehatan yang sudah di canangkan oleh pemerintah. Wacana dari pemerintah itulah yang mendasarkan munculnya proposal ini.wabah yang kita tidak tahu sampai kapan habisnya ini membuat metode dan sistem pembelajaran menjadi berubah 180 drajat, pelatihan yangan akan di taja ini menitik beratkan kepada kesiapan admin untuk dibekali pengetahuan dasar di dalam tooltools yang terakit pada sistem E-learning yang sudah di create sebelumnya, dan bertujuan untuk memberi bekat sebagai trainer di lingkungan kampus mitra nantinya. E-learning kampus secara umum dapat menyelamatkan keberlangsungan sebuah institusi pendidikan, dikarenakan adanya aplikasi yang dapat menopang keberlangsungan proses kegiatan belajar mengajar. Walaupun secara daring tetapi nuansa belajar masih bias dirasakan di masa pandemi ini.
\end{abstract}

Kata Kunci: E-Learning, Admin, YLERB, LMS Moodle Aplikasi

Abstract: At the golden page of Riau Rise Foundation, it has many levels of education under it such as the Lukman Edi Islamic High School (STAILe) education, formal education below the tertiary level as well as MTS (Madrasah Tsanawiyah) and MA (Madrasah Aliah). The current pandemic has disrupted all business and business sectors, as well as has an impact on the world of education. Many now learning systems and lecture systems have switched to online because they follow the health protocols that have been provided by the government. The government's discourse for that is what underlies the emergence of this proposal. This epidemic, which we do not know how long it will last, has resulted in a 180 degree change in the learning system. This training will focus on the admin's readiness to be equipped with basic knowledge in the tools assembled on the system. E-learning that has been created previously, and aims to provide blessings as trainers in the partner campus environment later. E-learning in general can save the continuity of an educational institution, because there are applications that can support the continuity of the teaching and learning process. Despite being brave, the nuances of learning can still be felt during this pandemic.

Keywords: E-Learning, Admin, YLERB, LMS Moodle Application

\section{Pendahuluan}

A. Analisis Situasi

Pengabdian ini merupakan lanjutan dari pengabdian sebelumnya yang mana sangat erat kaitannya dengan bagaimana pengetahuan dan pemahaman admin dalam penggunaan dan penerapan aplikasi yang sudah kita bangun tersebut. Admin nantinya akan diberikan pengetahuan dan wawasan serta di bekali dengan buku pentujuk agar dapat menjadi seorang trainer di kampus mitra ini. Pembekalan yang diberikan berdasarkan aplikasi dengan plugin yang sudah 
terinstall pada aplikasi E-learning ini. Semua ini terjadi karena adanya pergeseran sistem tatanan pendidikan yang di pengaruhi oleh wabah (pandemi).

Fenomena yang terjadi saat ini sudah kita rasakan kurang lebih 10 bulan terakhir, dan tidak ada 1 orang pun di dunia ini yang bisa menjamin sampaikapan fenomena wabah penyakit ini berakhir. Pandemic covid - 19 telah meluluh lantahkan sistem yang sudah berjalan selama ini dan dunia telah di kejutkan dengan kejadian hebat ini sehingga WHO mendiklair kan bahwa wabah ini menjadi pandemic global.

Penutupan sementara lembaga pendidikan sebagai upaya menahan penyebaran pendemi covid-19 di seluruh dunia berdampak pada jutaan pekerja, tidak kecuali di Indonesia. Gangguan dalam proses Administrasi langsung antara siswa dan admin berdampak pada menurunnya kualitas Administrasi. Beban itu merupakan tanggung jawab semua elemen pendidikan khususnya negara dalam memfasilitasi kelangsungan sekolah bagi semua steakholders pendidikan guna melakukan administrasi jarak jauh. Bagaimana mestinya Indonesia merencanakan, mempersiapkan, dan mengatasi pemulihan covid 19, untuk menekan kerugian dunia pendidikan di masa mendatang.

Proses Administrasi di sekolah merupakan alat kebijakan publik terbaik sebagai upaya peningkatan Sistem di sekolah. Selain itu banyak siswa menganggap bahwa administrasi adalah kegiatan yang sangat ribet, karna harus bolak balik ruangan Administrasi. Sekolah dapat meningkatkan keterampilan proses Administrasi dengan mengadakan pelatihan terhadap admin agar bisa melakukannya secara daring. Sekolah secara keseluruhan adalah media interaksi antar siswa dan guru untuk meningkatkan kemampuan integensi, skill dan rasa kasih sayang diantara mereka. Tetapi sekarang kegiatan yang bernama sekolah berhenti dengan tiba-tiba karena gangguan Covid-19. Sejauh mana dampaknya bagi proses Administrasi di sekolah? Khusus untuk Indonesia banyak bukti ketika sekolah sangat mempengaruhi produktivitas dan pertumbuhan ekonomi.

Miris seperti halnya cerita saya diatas tadi, bayak pihak pendiri yayasan memikirkan metode Administrasi apa yang pantas dan tepat untuk melanjutkan yayasan mereka, begitu juga halnya pada yayasan laman emas riau bangkit yang didirikan oleh H.M Lukman Edy. STAILe Pekanbaru adalah Sekolah Tinggi Agama Islam ( STAI ) HM Lukman Edy Pekanbaru adalah pendidikan tinggi agama Islam yang berada di bawah naungan Yayasan Laman Emas Riau Bangkit (YLERB ) dimana bapak HM Lukman Edy sebagai PEMBINA.STAI HM Lukman Edy telah mendapat operasional dari Direktorat Jendral Pendidikan Islam Departemen Agama Islam RI Nomor : Izin DJ.i/374/2010. STAI HM Lukman Edy memiliki (dua) jurusan : Pertama, Perbankan Syariah (S1); Kedua, Jurusan Hukum Keluarga (S1) Kedua Jurusan tersebut merupakan jurusan yang saat ini paling diminati masyarakat, karena memiliki prospek dan peluang kerja yang luas, serta karir menjanjikan. STAI HM Lukman Edy memiliki Misi "Mencetak Bankir \& Hakim Syariah". STAI HM Lukman Edy memiliki kurikulum modern dan telah disesuaikan dengan kebutuhan dunia kerja. Maka lulusan STAI HM Lukman Edy diharapkan mampu mengaplikasikan keilmuannya yang siap menjadi pelaku hakim syariah, bisnis, bankir syariah dan wirausahawan muslim yang berakhlaqul karimah. Berdasarkan dengan visi dan misi STAI HM Lukman Edy. STAILe Pekanbaru sudah terakreditasi BAN PT. 


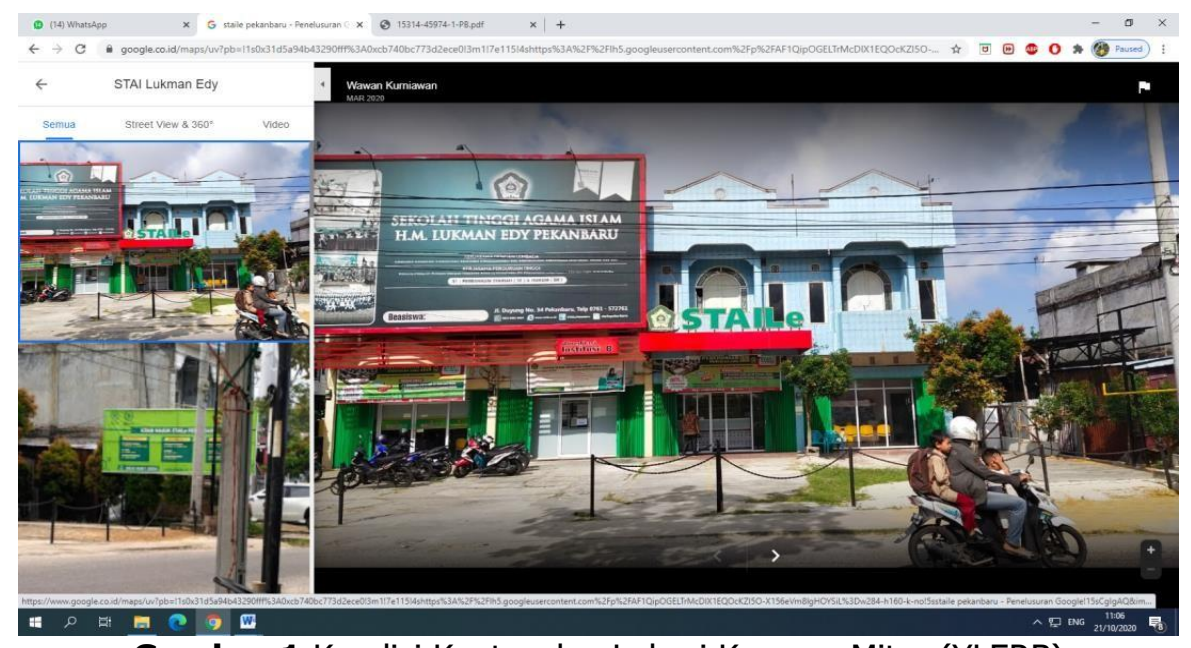

Gambar 1 Kondisi Kantor dan Lokasi Kampus Mitra (YLERB)

Untuk alamat lengkap dari tempat pengabdian mitra adalah di Jl. Duyung nomor $34 \mathrm{Kec}$. Marpoyan Damai, Kota Pekanbaru, Riau kode pos 28124, yang telah didirikan sejak tahun 2009 denagn berlokasi tepat pada pusat kota pekanbaru. Sekolah Tinggi Agama Islam H.M Lukman Edy Pekanbaru saat ini dipimpin oleh Ketua bernama Dr.Afiq Budiawan, M.H.I. perguruan tinggi ini mengutamakan peningkatan Sumber Daya Insani (SDI) dari pada mencari keuntungan belaka, bahkan dengan dukungan Pernerintah Daerah dan masyarakat serta komitmen yayasan untuk sarana dan prasarana perguruan tinggi, maka izin operasional itu dapat diraih dengan kegigihan yayasan untuk mendapatkan izin operasional.

Sementara itu penerapan Solusi E-Learning Interaktif yang digunakan untuk model Administrasi tatap muka dan Administrasi on-line yang bisa menggabungkan kedua sisi, juga berhasil dalam mengatasi keterbatasan Administrasi on-line sambil tetap memberi manfaat bagi fleksibilitasnya dan keseluruhan penghematan biaya. Blended Interaktif dapat mendorong Admin untuk memanfaatkan sebaik-baiknya kontak face-to-face dalam mengembangkan sistem. Persiapan dan tindak lanjutnya dapat dilakukan secara on-line.

Berdasarkan hasil obervasi dan interview, maka tim pengusul program pengabdian kepada Masyarakat (PKM) menawarkan sebuah solusi terhadap permasalahan yang dihadapi oleh yayasan tersebut, melalui kegiatan Pelatihan ELearning untuk Admin ini dapat memudahkan proses Administrasi dimasa Pandemi.

E-learning merupakan istilah yang berasal dari bahasa inggris,learning berasal dari suku kata learn yang artinya belajar. maka makna umum yakni pembelajaran yang di dukung dengan media elextronik, dengan demikian mengandung makna pola pembelajaran yang mengandung unsur pencampuran, atau penggabungan antara satu pola dengan pola yang lainnya.

E-Learning atau Hybrid Learning adalah pembelajaran yang memadukan antara komponen online dan komponen tatap muka. Kenyataannya, program belajar yang mengandung komponen online sekecil apapun (misalnya : situs web pendukung, akses email ke instruktur, daftar bacaan online) kadang-kadang disebut sebagai E-Learning.

Penerapan E- Learning tidak terjadi begitu saja. Tapi, terlebih dulu harus ada pertimbangan karakteristik tujuan Administrasi yang ingin kita capai, aktifitas pembelajaran yang relevan serta memilih dan menentukan aktifitas mana yang 
relevan dengan konvensional dan aktifitas mana yang relevan untuk online learning

Program PKM ini terfokus pada Yayasan YLERB Pekanbaru yang sistem Administrasi masa pandemic ini hanya menggunakan google meet atau pun Zoom metting sehingga belum bias dikatakan sebagai sistem pembelajaran, yang mana dua aplikasi tadi hanya pendukung untuk reapat secara online. Nantinya LMS yang akan di kembangkan dan dibangun ini (development) dapat menghasilakan sebuah sistem Administrasi yang mana di dalam nya terdapat sistem yang dapat memudahkan admin. Dari beberapa manfaat kegiatan PKM ini, tim pengusul akhirnya merumuskan judul kegiatan ini menjadi "Training Of Trainer E-Learning Bagi Admin Di Sekolah Tinggi Agama Islam Lukman Edy (STAILE)"

\section{B. Permasalahan Mitra}

Sebagai mitra dalam pelaksanaan kegiatan Program Kemitraan Masyarakat (PKM) pada pengabdian masyarakat ini yang lebih dikenal dengan istilah Ibm adalah Sekolah Tinggi Agama Islam Lukman Edy (STAILe) Pekanbaru, kecamatan Marpoyan Damai, Kota Pekanbaru.yang beralamat lengkap di Jl. Duyung No.34, Tangkerang Barat, Kec. Marpoyan Damai, Kota Pekanbaru, Riau kode pos 28124 dengan nomor telfon (0761) 572761. Berdasarkan analisis situasi dapat teridentifikasi beberapa permasalahan yang dihadapai oleh mitra, yaitu:

1. Susahnya proses administrasi dikarenakan pandemi.

2. Pelatihan dalam pemakaian fitur E-learning yang sudah ada bagi admin

3. Kurang nya pengetahuan admin serta pihak kampus terhadap IT.

4. Media meeting yang digunakan saat ini tidak dapat menyimpan data pembelajaran seperti : bahan dan materi ajar, soal-soal dan quiz perkuliahan.

\section{Metode Pelaksanaan}

A. Solusi yang ditawarkan

Berdasarkan penggalian informasi awal terhadap mitra Program Kemitraan Masyarakat, terdapat beberapa tawaran solusi penyelesaiannya sebagai berikut:

1. Pembentukan atau pembinaan dari yayasan mengenai device / perangkat yang akan disediakan oleh yayasan diharapkan dapat mengatasi permasalahan administrasi dan mampu menjadi wahana dalam memfasilitasi administrasi di kampus mitra.

2. Menambah pengetahuan dan keterampilan para admin di kampus mitra tentang tools tools yang ada di dalam E learning yang sudah di buat sebelumnya.

3. Memotivasi admin untuk tetap bersemangat dalam bekerja, begitu sebaliknya untuk dosen maupun tenaga pendidik lainnya

B. Mekanisme Pelaksanaan Kegiatan

Adapun mekanisme pelaksanaan Program Kemitraan Masyarakat ini memiliki beberapa langkah yang terdiri dari 4 tahapan kegiatan; perencanaan, pelaksanaan, monitoring kegiatan, dan evaluasi. Di mana mekanisme kegiatan Program Kemitraan Masyarakat ini akan dijelaskan secara terperinci dalam diagram dibawah ini: 


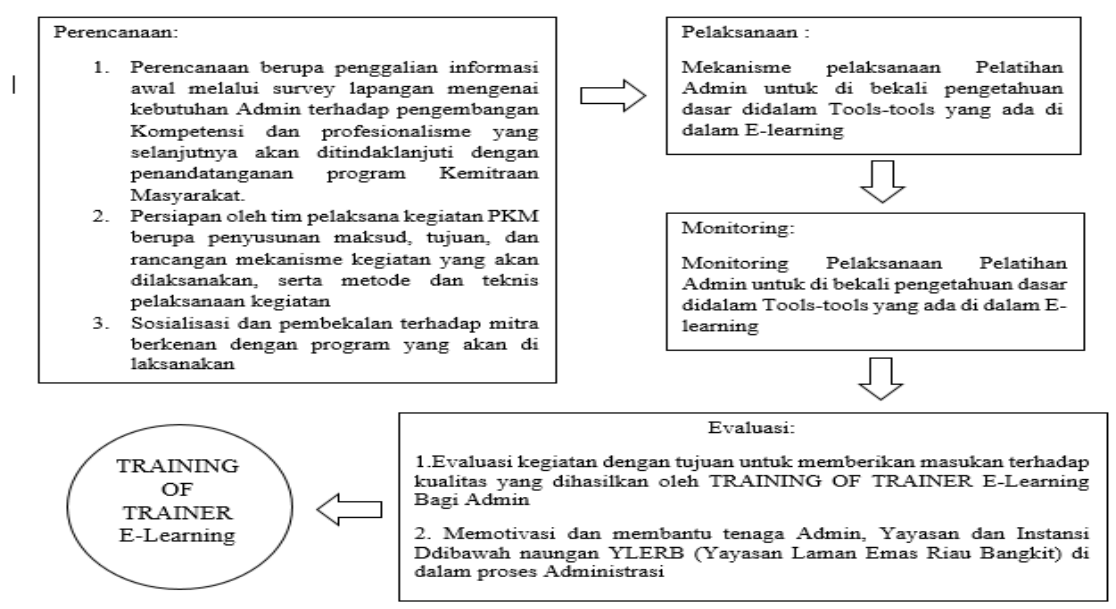

Gambar 2 Metode Pelaksanaan Kegiatan

\section{Hasil dan Pembahasan}

Pada saat pelaksanaan kegiatan ini penulis dan tim banyak sekali mendapatkan Apresiasi, terutama oleh pemilik yayasan Laman Emas Riau Bangkit yang di singkat dengan (YLERB) para peserta dan sekaligus oleh kepala Sekolah Tinggi Agama Islam lukman edy (STAILE) Pekanbaru yang merasa dapat mengupgrade pengetahuan mereka tentang Tools tools yang ada didalam sistem E learning yang sudah di buat sebelumnya. Apalagi di masa pandemic ini dibutuhkan sekali adanya sebuah sistem pendukung untuk administrasi agar segala macam yang berkaitan dengan administrasi dapat terdata dan ter record dengan baik.

Adapun pelaksanaan kegiatan ini dilakukan di ruangan laboraturium Komputer di Kantor STAILE Jalan Duyung Pekanbaru teapatnya di lantai 2 gedung induk, yang memiliki sarana penunjang yang sangat memadai dan sangat respresentatif demi lancarnya kegiatan sosialisasi serta pendapingan pelatihan ini, pelaksanaan kegiatan ini di lakukan pada hari
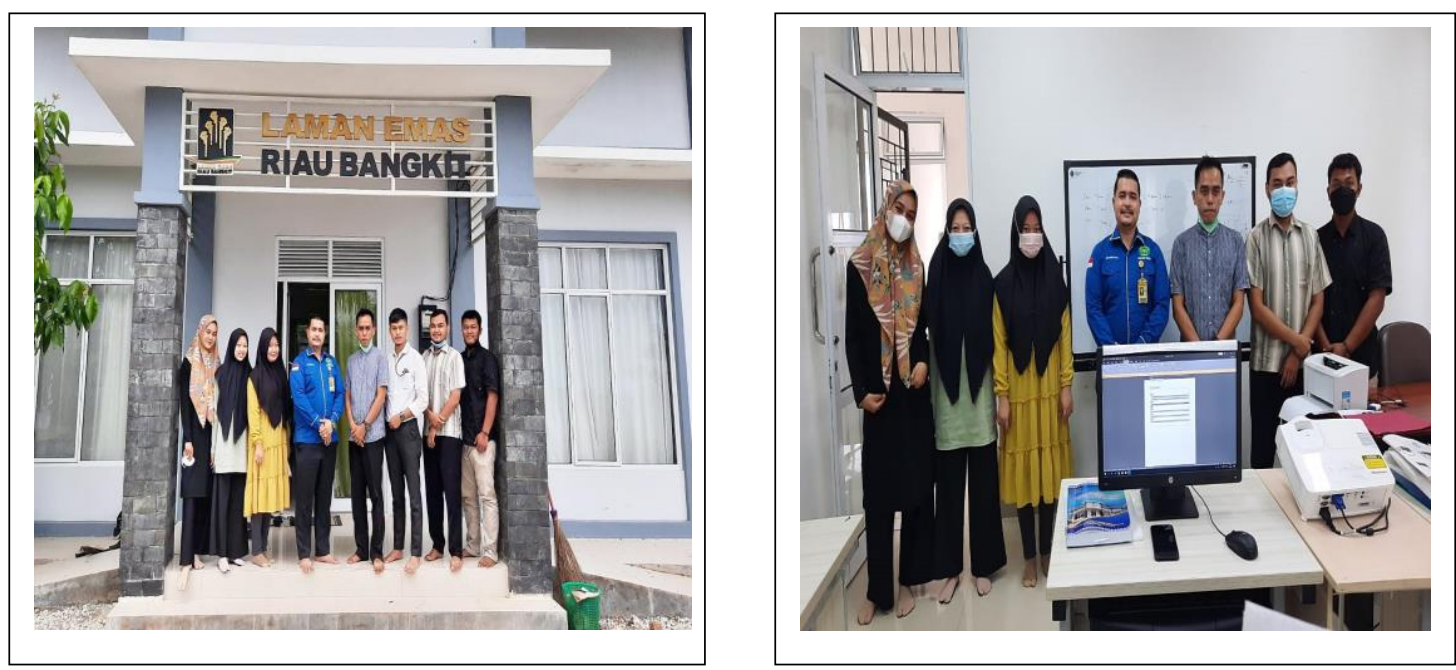


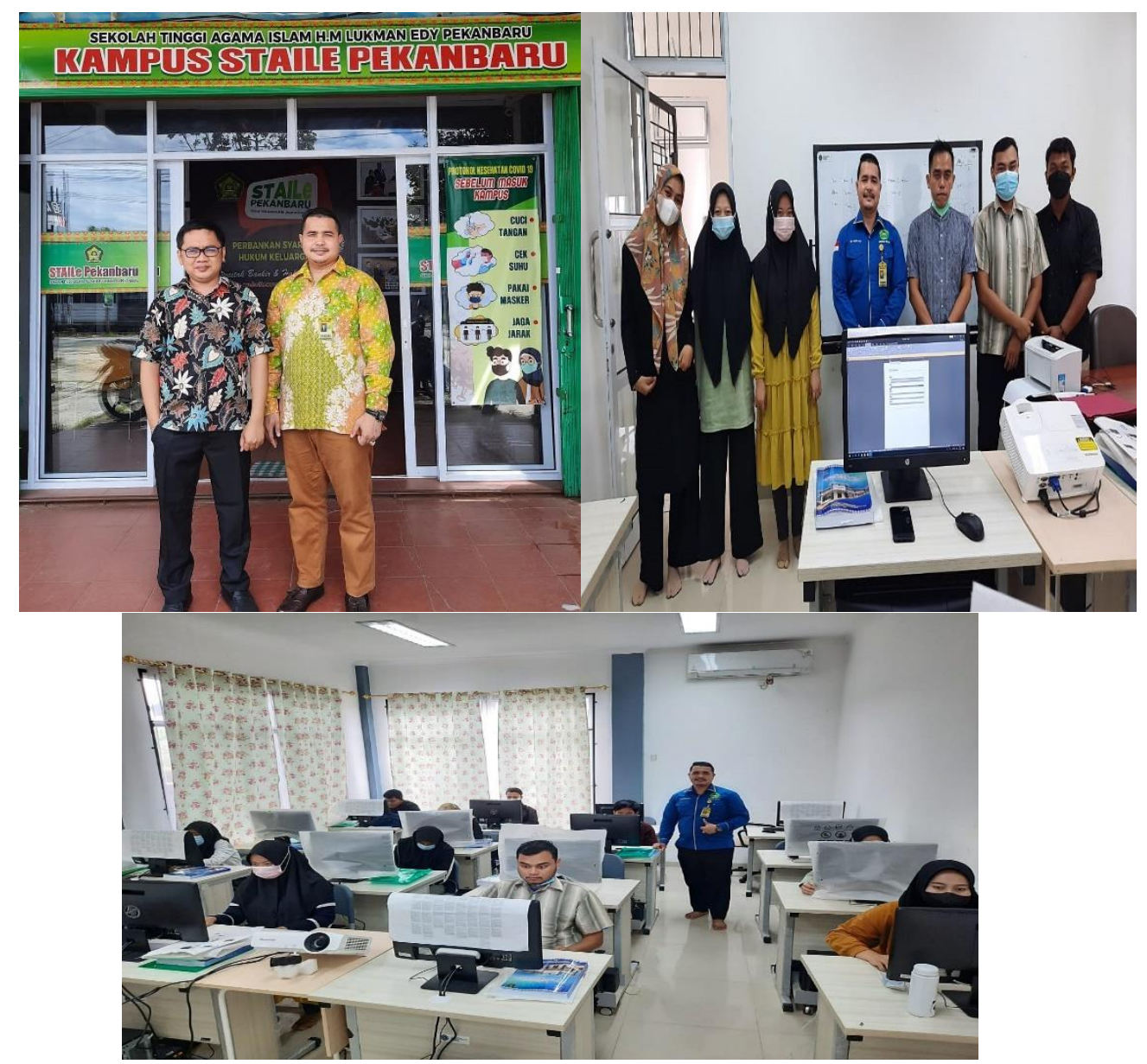

Tahapan tahapan yang pemateri sampaikan antara lain yaitu :

a. Melakukan Pembekalan pemahaman bagi admin mengenai tools tools yang berkaitan dengan sistem E learning yang sudah di buat sebelumnya

b. Melakukan penjelasan untuk fungsi dan kegunaan dari tools yang ada di dalam E learning

c. Penyebaran Kuisioner kepada peserta pelatihan terhadap apa yang sudah di dapat.

d. Membuat akun administrator kepada seluruh peserta

e. Menjelaskan fitur dan memberikan akses fitur dan penambahan aktifiti dan resousce pada e-learning nya, mengikuti prosedur sesuai buku panduan yang ada.

Kegiatan pengabdian ini dilakukan dengan mengikuti anjuran dari pimpinan kampus mengenai penerapan protokol kesehatan berdasarkan instruksi dan penerapan peraturan pemerintah daerah dan pusat dengan adanya PPKM (Pemberlakuan Pembatasan Kegiatan Masyarakat), bahwasanya dibatasi pengumpulan dalam jumlah besar serta seluruh peserta wajib menjaga jarak dan memakai masker.

\section{Mengubah Identitas}

Pada saat ini, kita berperan sebagai Administor atau Admin. Sebagai Admin kia bisa melakukan apa saja terhadap portal e-learning yang sudah kita buat tersebut. Identitas portal e-learning dapat kita ubah sesuai dengan keperluan lembaga kita atau keinginan kita. 
1. Loginlah ke portal E-learning sebagai Admin

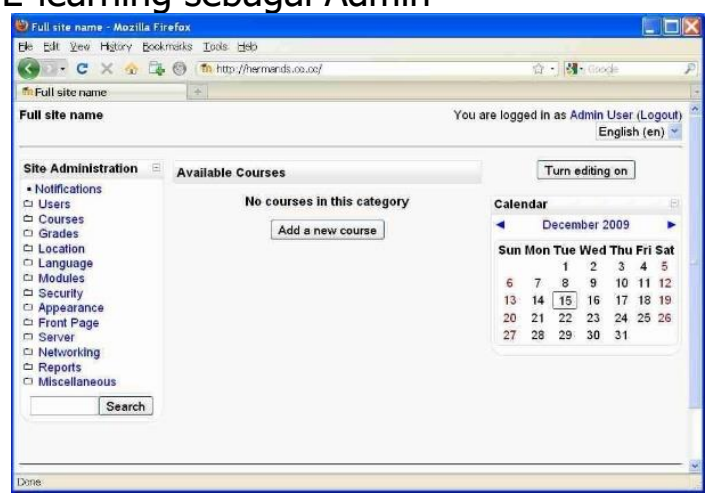

Gambar 3 Tampilan portal E-learning

2. Akses Front Page $>>$ Front Page settings. Isilah identitas elearning anda

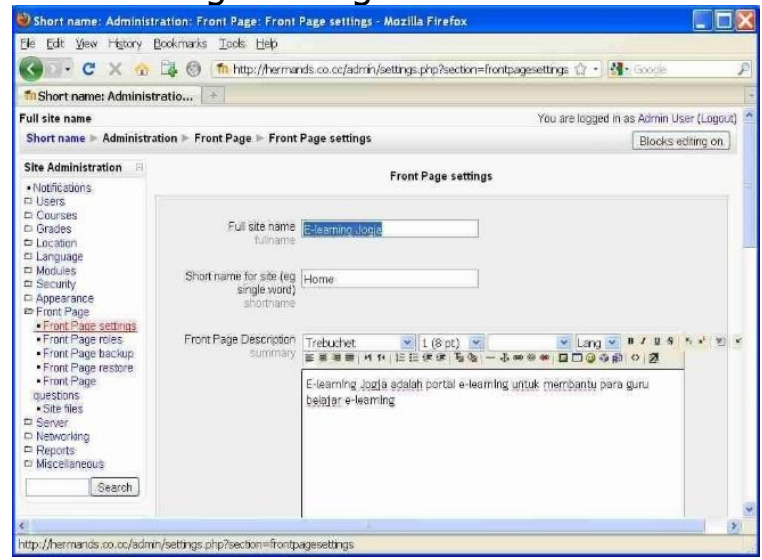

Gambar 4 Tampilan Akses Front page

3. Anda dapat mengatur tampilan halaman depan baik tampilan ketika sebelum login maupun tampilan ketika sesudah login

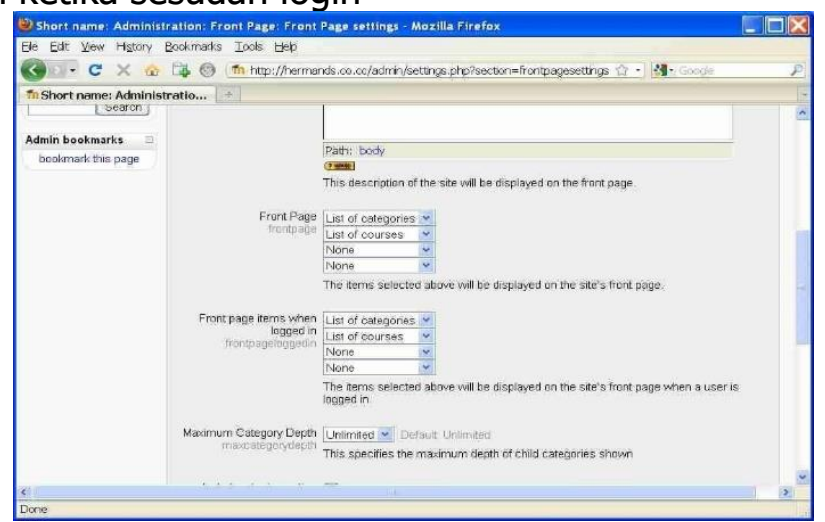

Gambar 5 Tampilan Halaman Setting 
4. Tampilan sesudah pengaturan tersebut adalah sebagai berikut.

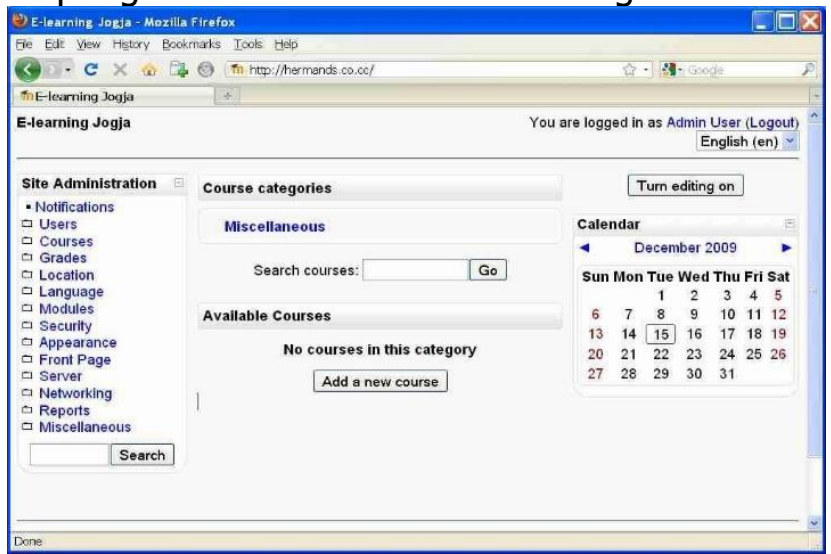

Gambar 6 Tampilan Halaman Selesai Setting

\section{Kesimpulan}

Berdasarkan Hasil data daro kegiatan pelatihan Admin tentang pengetahuan dasar di dalam Tools tools E-Learning yang sudah ada sebelumnya, Maka penulis dapat mengambil beberapa kesimpulan yaitu:

A. Pengetahuan peserta pelatihan tentang tools tools yang ada di dalam sistem ELearning Secara keseluruhan mengalami peningkatan

B. Dengan adanya pelatihan ini dapat merecord bagaimana kegiatan Administrasi di Sekolah Tinggi Agama Isllam Lukman Edy (STAILE) Kota Pekanbaru sehingga dapat mendorong Admin untuk lebih meningkatkan Administrasi Agar lebih baik dan terstruktur

C. Antusisasme dari para peserta pelatihan ini menunjukkan peningkatan yang signifikan untuk bagian Administrasi di Sekolah Tinggi Agama Islam Lukman Edy (STAILE) Kota Pekanbaru

\section{Ucapan Terima Kasih}

Alhamdulillahirobil'alamin, rasa syukur kepada Allah subhaanahu wa ta'ala. Hanya dengan rahmat dan hidayah-Mu Laporan Akhir Pengabdian kami yang berjudul "Training Of Trainer E-Learning bagi Admin di Sekolah Tinggi Agama Islam Lukman Edy (STILe) Pekanbaru" dapat diselesaikan. Kegiatan ini dilakukan dalam rangka mewujudkan salah satu dari Tri Dharma Perguruan Tinggi serta peningkatan pengetahuan penulis dan menambah literasi jurnal pendidikan. Penulis menyadari sepenuhnya bahwa tanpa adanya bantuan dari berbagai pihak, Penulis akan banyak menemui kesulitan dalam penyusunan laporan ini. Untuk itu Penulis ucapkan terimakasih kepada Universitas Lancang Kuning yang telah memberikan dukungan melalui LPPM berupa pengawasan terhadap keberlangsungan penelitian ini. Penulis juga mengucapkan terimakasih kepada pihak Fakultas Ilmu Komputer Universitas Lancang Kuning selaku penyedia dana sekaligus sebagai mitra kerjasama pertama. Akhirnya semoga hasil penelitian ini dapat bermanfaat bagi penulis dan dunia akademis khususnya serta masyarakat umumnya. 


\section{Daftar Pustaka}

Andriani, r., \& kasriyati, d. (2018). Pembuatan media pembelajaran berbasis multimedia bagi mahasiswa kampus dasar (sd) kecamatan rumbai kota pekanbaru provinsi riau. J-abdipamas (jurnal pengabdian kepada masyarakat), 2(2), 119-126

Arsyad, azhar. 2018. Media pembelajaran. Jakarta: pt. Raja grafindo persada arsyad, azhar. 2021. Media pembelajaran. Jakarta: pt. Raja grafindo persada Gerlach \& elly. 2018. Teaching and media. Englewood cliffs, new jersey: prentice hall, inc Kurniawan, k., andriani, r., \& kasriyati, d. (2017). Pengembangan media animasi untuk pembelajaran bahasa inggris sekecamatan rumbai kota pekanbaru. Dinamisia: jurnal pengabdian masyarakat, 1 (1, des), 68-73

kurniawan, nanang. 2014. Kurikulum 2011 dan pergeseran peran mahasiswa.

rusman, dkk. 2017. Pembelajaran berbasis teknologi informasi dan komunikasi: mengembangkan profesionalisme mahasiswa. Jakarta: pt. Rajagrafindo persada."

sa'diyah, halimatus. 2015. Peran pendidikan pada era globalisasi. Didapat dari: smaldino, sharon e, et all. 2015. Instructional technology and media for learning. New Jersey: pearson prentice hall."

soedijarto. 2011. Profesionalisme mahasiswa (pendidik) dalam era globalisasi, implikasi, peluang dan tantangannya. Didapat dari:

wahyono, budi. 2016. Peran pendidikan dalam pembangunan nasional dan/atau sebaliknya. Didapat dari: 